\title{
Mysterious Mineral: Fluoride
}

\author{
Ram Mohan Sai Deepika1', Shahsidhar Kurpad Nagaraj², Pattrapalli Nadipanna Sreeramulu ${ }^{3}$
}

\author{
${ }^{1}$ Department of Biochemistry, Sri Devaraj Urs Medical College, Tamaka, Kolar, Karnataka, India. ${ }^{2}$ Department of \\ Biochemistry, Sri Devaraj Urs Medical College, Tamaka, Kolar, Karnataka, India. ${ }^{3}$ Department of General Surgery, Sri \\ Devaraj Urs Medical College, Tamaka, Kolar, Karnataka, India.
}

\section{ABSTRACT}

\section{BACKGROUND}

Elements on earth since ages are known to have their own importance for normal functioning of an organism. Urbanization globally has changed constituents of soil, air and water resulting in gradual destruction of ecological balance. Deficiency or toxicity of essential minerals leads to disturbances or abnormalities in living system. Once deficient, now a common toxic molecule in toxicology and research is "fluoride". Fluoride causes various types of fluorosis namely, dental, skeletal and non- skeletal fluorosis. In recent days, due to decrease in ground water level there is a rise in water table leading to leaching of rocks which is main route of water fluoridation. Principle behind water and dental product fluoridation is protection against demineralization of dentine and bone matrix (Enamel) ultimately for maintaining mineral matrix. fluoride from external sources helps preventing cariogenic action by disrupting bacterial cell wall and fluoride in enamel matrix that is Fluorapatite which is stable than hydroxyapatite since fluorapatite maintains strong crystal matrix preventing dissolution of teeth minerals. Dental fluorosis is an early sign of detecting non-skeletal fluorosis. There is a notion on non-skeletal fluorosis that, fluoride damage DNA of various cells in many principle organs of metabolism causing mutation in signalling pathway of enzymes and proteins responsible of metabolism leading to metabolic damage and depreciation in normal cell functioning. Fluorosis is a natural phenomenon due to environmental imbalance, the solution for these disturbances also lays in natural forms, hence, antioxidants against fluoride found in vegetations and plant extracts. To name a few plant sources for counter action are: coffee infusions of different types of beans, Vit E rich sources such as olives, broccoli etc, curcumin a compound in turmeric activates antioxidants cascade in our body, resveratrol prevents ROS generation by breaking free radical chain reaction and prevents lipid peroxidation found in grapes, nuts etc., tamarind fruit pulp rich in vit $\mathrm{C}$ may ameliorate fluoride toxicity by preventing ROS generation, Moringa leaves and its seeds are best in fluoride absorption and excretion from body, also used for water defluoridation, vit $\mathrm{C}$ rich Emblica officinalis helps deteriorate effect of fluoride on IQ by protecting cholinergic neurotransmitters against fluoride induces ROS damage. Fluoride if introduced in routine blood investigations especially in fluoride belts will help in better diagnosis of underlying cause of a pathology or disorder. As a result, our future generations will be safe and protected free from pathologies and damages caused by fluorosis. This review article outlines the foundation of fluoride and fluorosis in present era concluding with simple methods in prevention of fluorosis.

\section{KEY WORDS}

Dental Fluorosis, Deficiency, Non- Skeletal Fluorosis, Skeletal Fluorosis, Toxicity.
Corresponding Author: Dr. Shashidhar Kurpad Nagaraj, Department of Biochemistry, Sri Devaraj Urs Medical College, Tamaka, Kolar-563103, Karnataka, India.

E-mail:drshashikn1971@yahoo.co.in

DOI: $10.14260 / \mathrm{jemds} / 2019 / 781$

Financial or Other Competing Interests: None.

How to Cite This Article: Deepika RMS, Nagaraj SK, Sreeramulu PN. Mysterious mineral: fluoride. J. Evolution Med. Dent. Sci. 2019;8(48):3617-3623, DOI: 10.14260/jemds/2019/781

Submission 18-09-2019, Peer Review 14-11-2019, Acceptance 20-11-2019, Published 02-12-2019. 


\section{BACKGROUND}

All elements in the periodic table have their importance in the ecosystem whether it is a gas or a liquid or a solid. They will be required as an atom or molecule or compound for smooth functioning of organisms. Toxicity starts when consumed or exposed beyond limit tolerable by an organism. Nature keeps a balance between all elements until unless we do not disturb them, any interferences will destroy the balance.(1) Urbanization globally has changed constituents of soil, air and water resulting in gradual destruction of ecological balance a proportionate to increase in destruction as well as development. Different areas of globe face different problems ending up in various endemic disorders. India being designated as capital of diabetes is also considered more prone to many types of cancers and immune compromised infections.(2) There are many confounding factors causing these diseases which again depend on the state and its geographical location. Geographical location includes type of flora and fauna, soil and rocks responsible for varying constituents of elements in local environment.(2)

One such element increased due to natural imbalance is 'fluoride'. Fluoride is high reactivity and electronegative characteristic hence found in bound form.(2) Occurrence of fluoride is mainly in natural waters such as sea water, ground water, lakes and ponds. Other forms are found in earth's crust as solids and in atmosphere as gas.(2) Therefore, it is considered as omnipresent element and considered for research.(2)

In recent days, due to decrease in ground water level there is a rise in water table leading to leaching of rocks which is main route of water fluoridation.(3) India is one of the country to be affected by endemic fluorosis among which majority of dry and semi- arid states such as, Tamil Nadu, West Bengal, Gujarat, Rajasthan, Karnataka, Andhra Pradesh and Uttar Pradesh are affected.(3-6) Though it is proved that fluoride helps preventing dental caries when consumed in optimum level, excess fluoride accumulates in calcium rich sites such as teeth, bone, muscle etc., leading to erosion of surface and hampers normal cell functioning.(7) Fluoride (F) does not change physical appearance of consumables therefore until unless it is estimated, we cannot conclude presence of fluoride.(7) Hence fluoride must be considered as one among the elements to be monitored during water purification, treatment and plantation to prevent toxicity. Current review outlines water Defluoridation and fluoride analysis in support with fluorosis.

\section{History}

As mentioned earlier, fluoride when consumed in optimum concentration has a protective action, its toxicity causes illeffects such as: bone disorders (skeletal fluorosis), dentine abnormalities (dental fluorosis), organ damages (visceral fluorosis) and vascular damage (vascular fluorosis). (8) History of fluoride fortification in drinking water started in 1934 by Dean in USA to prevent dental caries. Fortification was successfully implemented during 1950 in toothpaste and dairy products.(8) Many researches and studies were performed to confirm fluoride side effects on organisms. Animal studies resulted in osteosarcoma of very few rats with chronic high exposure to fluoridated water.(8)
Epidemiological field studies may provide furthermore valid information about fluoride and its ill effect in society of fluoride exposed population.

Way back in 1934, Dean and Evolve defined dental fluorosis as 'chronic, fluoride induced condition where in, dentine development and mineralization are disrupted resulting in eroded enamel'.(9) Dean in 1934 framed Dean's index to study dental fluorosis staging based on teeth opacity as-

i. Normal.

ii. Very mild to mild: $50 \%$ opacity affected.

iii. Moderate: more than $50 \%$ opacity affected.

iv. Severe: complete tooth damaged including pitting and physical changes.

Followed by other indices often compared are Thylstrup and Fejerskov (TF) and Tooth Surface Index of Fluorosis (TSIF). $(10,11)$

Fluoride apart from affecting calcified tissues also affects cellular chemistries such as cellular organelles, enzymes etc. Effect of fluoride on enzymes was studied by Rall and Sutherland in the year 1958 on signal transduction.(12) Major contribution to fluoride research from 1930's to till date is by USA, China, Australia and India.

\section{Chemistry}

Fluoride is highly reactive electronegative halide with atomic number 9 and oxidation state-1.(3) Naturally, fluoride occurs in combinations as compounds complexes, since; it is highly electronegative and reactive halogen. According to Bureau of Indian Standard (BIS) Serum fluoride conc is $0.01-0.05 \mathrm{mg} / \mathrm{L}$ and urine level must be $0.1-1.0 \mathrm{mg} / \mathrm{L}$. water level of fluoride must be $<1 \mathrm{mg} / \mathrm{L}$. ${ }^{(3)}$

$\mathrm{F}$ in earth's crust is about $0.3 \mathrm{~g} / \mathrm{Kg}$ in form of minerals such as, (3) Cryolite: Found in Russia, USA and North America, used in production of aluminium.(7) Fluorspar: Deposited in North America, Spain, Russia and Mongolia. Utilized by Glass manufacturers and as flux in iron industries. Fluorapatite: Found in igneous and metamorphic rocks in nature. Also found in bone and teeth of organisms to maintain structural integrity in combination with calcium.(7)

\section{Fluoride Distribution in India}

According to Bureau of Indian Standard (BIS) and WHO, acceptable fluoride limit in potable water is $1 \mathrm{ppm}$ and 1.5 ppm respectively.(13) Nalgonda district, Telangana was reported to contain minimum 0.5 to maximum $29 \mathrm{ppm}$ Fluoride in bore well water documented by Saxena and Sewak, in the year 2015.(14) Studies in India on human dental and skeletal fluorosis was first reported during 1937 in Nellore and Madras Presidency.(15,16) Since then India is considered as endemic fluorosis country among affected 24 countries across the world. India lies in fluoride belt with 12 million fluoride deposits in Indian earth's crust.(3) Recently, parts of Telangana, Rajasthan, Punjab, Karnataka, Tamilnadu, Kerala and Maharashtra are considered fluorosis endemic areas where water fluoride levels are crossing acceptable BIS fluoride levels. (14,17-20)

\section{Sources of Fluoride}

Intake of fluoride can be from either natural resources or manmade exploitation of nature. Natural sources are: 
drinking water from bore well, vegetation grown in fluorotic water and fishes grown in natural water bodies. Sources of manmade pollution causing fluorosis are: cosmetics, drugs, air around industries emitting fluoride, mining, dental products such as mouth wash and toothpastes.(21,22) Chemically, inorganic fluoride is more soluble in water than organic fluoride hence; inorganic fluoride is easily absorbed by body causing increased fluoride toxicity.(2) Major rocks called the reservoir of fluoride complexes are: granite and natural rocks, found in Rajasthan, Telangana and Karnataka hence these areas are named fluoride endemic areas.(1)

Fluoride is present in stratosphere and lithosphere of atmosphere, earth's crust and natural water to a maximum extent of $100 \mathrm{ppm}$.(2) Fluoride is ionic form of fluorine, highly reactive, hence found in combination with other minerals majorly as hydrogen fluoride, calcium fluoride salts of hexafluorosilicates, micas, appetites and fluorite responsible for fluoride leaching into groundwater, among which hydrogen fluoride is accepted by our body tissues for absorption and metabolism.(23) Increase in acidity increases fluoride absorption irrespective of absorbing source (flora and fauna).(2)

Apart from natural exposure to $\mathrm{F}$, other routes are occupational exposure such as workers of coal mining, aluminium industries, fertilizers and pesticides manufacturing industries and fuel extraction plants are more prone for fluoride accumulation through inhalation.(24)

It is known that $1.9 \mathrm{ppm}$ of fluoride means $0.1 \mathrm{mM}$.(25) Acute toxicities of fluoride present with nausea, vomiting, diarrhoea, acidosis and cardiac arrhythmias.(1) Use of fluoride supplements during the first 6 years of life and especially during the first 3 years is associated with a significant increase in fluorosis.(26) Chronic toxicity (Fluorosis) is a slow, progressive, degenerative disorder caused by an excessive fluoride exposure, which is of three types: skeletal fluorosis (Bone deformities, spinal compressions, restricted movements of joints), dental fluorosis, and non-skeletal fluorosis affecting all soft tissues.(27) In India, renowned researchers in fluorosis documented that both to skeletal and non- skeletal fluorosis. AK Susheela et al., demonstrated molecular level mechanism of fluorosis in soft tissues and nerve cells. ${ }^{(28)}$

Worldwide distribution of fluoride in groundwater is pictured in Fig. 1. Below.

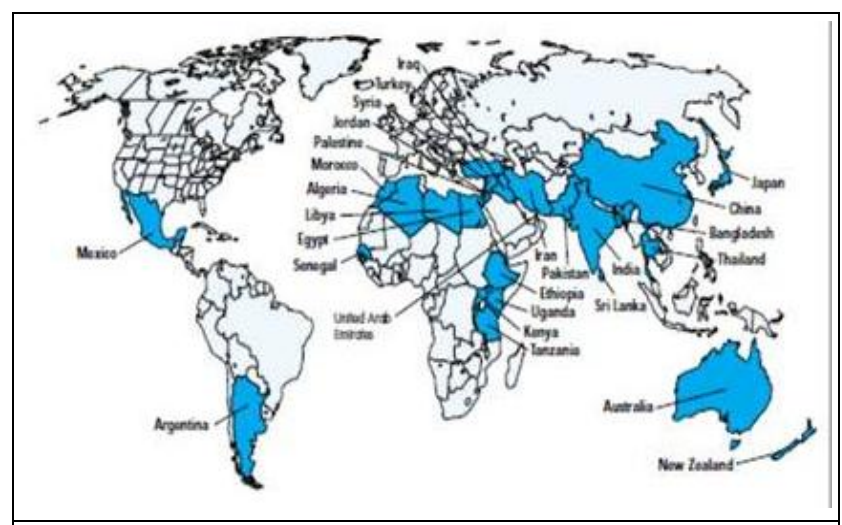

Figure 1. UNICEF Publication on Water, Environment, Sanitation and Hygiene, UNICEF Water Front Issue 13 December 1999

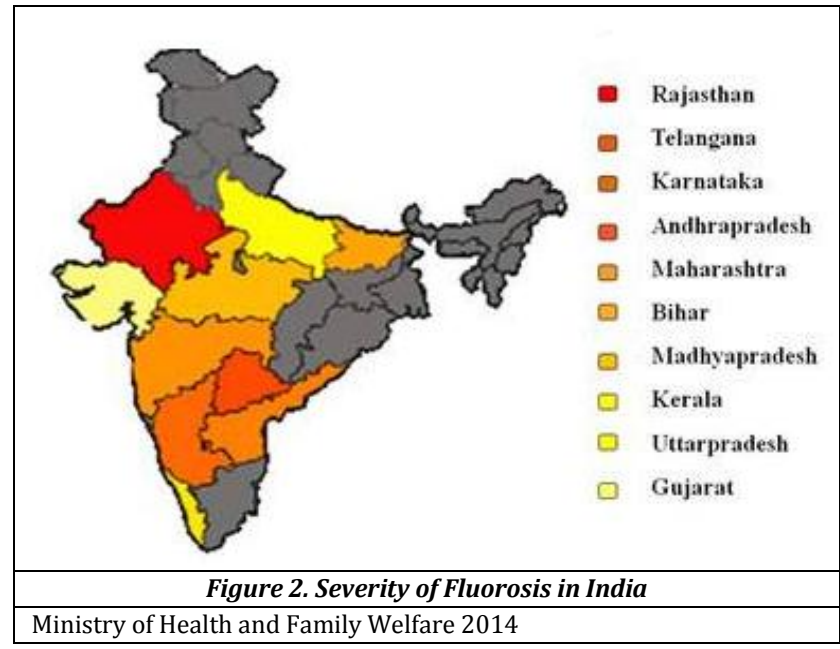

\section{Physiological Role of Fluoride}

Principle behind water and dental product fluoridation is protection against demineralization of dentine and bone matrix (enamel) ultimately for maintaining mineral matrix.

Process of caries prevention: Teeth enamel is composed of majorly hydroxyapatite with other supporting components such as calcium, phosphate, hydroxide and fluoride for maintaining $\mathrm{pH}$ around enamel. During cariogenic and microbial attack, bacteria tend to release $\mathrm{H}^{+}$ions from consumed carbohydrates resulting in decreased $\mathrm{pH}$ causing increased acidity of oral environ.(23) fluoride from external source helps preventing cariogenic action by disrupting bacterial cell wall and fluoride in enamel matrix that is Fluorapatite which is stable than hydroxyapatite since fluorapatite maintains strong crystal matrix preventing dissolution of teeth minerals.(29-31) Amongst many bacteria, Streptococcus mutans (S. mutans) tends to have cariogenic effect and progression and it is also sensitive to F.(30)

$\mathrm{F}$ in osteoblasts: osteoblasts are mineralizing cells in bone matrix. Role of fluoride in bone is similar to that of teeth but there are no much human in vivo studies rather many animal studies stated that bone mineralization is stimulated by $\mathrm{F}$. Various studies and models proposed by researchers from 1988 to 2005 concluded that AlFx (Aluminium Fluoride) and $\mathrm{NaF}$ (Sodium Fluoride) are active compounds for activation of osteoblasts through alkaline and acid phosphatase activation. ${ }^{(2,33)}$ Accepted hypothesis is, fluoride in low doses tend to activate bone forming enzymes and high doses will lead to hypermineralisation and frequent bone fracture.(31)

There is a notion on non-skeletal fluorosis stating that, fluoride damage DNA of various cells in many principle organs of metabolism causing mutation in signalling pathway of enzymes and proteins responsible of metabolism leading to metabolic damage and depreciation in normal cell functioning.(34)

\section{Metabolism of Fluoride Ingestion and Absorption}

Recommended fluoride intake to prevent acute disorders is 1 $\mathrm{mg} / \mathrm{Kg}$ body weight.(35) Toxicity invades if the limits are crossed leading metabolic alkalosis suggested by Whitford et al. in animal studies with acute infusion of inorganic fluoride.(36) Commonly used complex of fluoride in drinking water is Sodium fluoride and Fluoric acid.(37) Fluoride in water is readily absorbed than in food, orally, fluoride is 
absorbed from food as sodium monofluorophosphate (SMP) complex.(38) fluoride absorption is effective in complex form than in ionic form.(39) Oral mucosal absorption of fluoride contributes to plasma fluoride and is ionized in oral cavity at nearly neutral $\mathrm{pH}$ consequently free fluoride is released into gastric space for absorption.(39) Gastric space is acidic environment, favouring fluoride absorption by stomach lining especially the first part of duodenum through passive transport under the influence of $\mathrm{pH}$ or $\mathrm{HF}$ gradient across the membrane.(39) Increase in $\mathrm{pH}$ increases $\mathrm{HF}$ dissociation leading to decreased fluoride absorption by gastro intestinal tract (GIT) due to low permeability of fluoride ion across cell membrane as a result of poor shell of hydration radius.(38) Other routes of fluoride ingestion may be inhalation absorption through fluoride in air absorbed by alveolar epithelial cells and dermal absorption evident only from Military and animal studies. ${ }^{(40,41)}$ fluoride absorption is delayed by cations such as calcium, magnesium, sodium, manganese etc forming insoluble complexes and decreasing the movement across cell membrane. This is the reason why fluoride tablets are consumed in empty stomach making maximum bioavailability of fluoride in therapeutics.

\section{Distribution}

Absorbed fluoride is distributed through blood to all organs and tissue. During this stage of distribution, ionic fluoride plays significant role in deposition than nonionic F. Ionic fluoride can easily complex with the matrix of target cell causing therapeutic or ill effects.(38,42) Hierarchy of fluoride deposition is calcified tissues such as bone and teeth, soft tissues such as cartilages and muscles, tissue cells such as islets in renal cells, nervous system, placenta etc.(43-46) About $50 \%$ of absorbed fluoride is found deposited in bone reversibly by covalent bonding resulting in Fluorapatite formation.(47) In soft tissues, fluoride is in organic state since it protonates with $\mathrm{H}$ in intracellular space to form $\mathrm{HF}$ and is rapidly fluctuating, this is free form of fluoride and responsible to maintain steady state of fluoride concentration between cell and cellular environment.(48) Across the cell membrane there happens either co- transport with hydrogen ion $\left(\mathrm{H}^{+}\right)$or in exchange with hydroxyl ion $\left(\mathrm{OH}^{-}\right)$which indicates presence of fluoride specific transporter.(26)

\section{Excretion}

Major route of fluoride excretion is through urine by kidneys. Inorganic fluoride deposits in bone, almost $100 \%$ of inorganic fluoride is not excreted, as bone mineralization decreases plasma fluoride leading to more excretion of F.(46) Process of excretion has similar kinetic as absorption. fluoride is excreted through passive diffusion; decrease in $\mathrm{pH}$ increase in excretion and both are dependent on $\mathrm{pH}$ gradient across tubular cells of nephrons.(46) pKa for fluoride absorption and excretion must be around 3.5. (38) In total, factors affecting fluoride excretion are $\mathrm{pH}$ gradient across tubular cells, amount of fluoride ingested changes in extracellular fluid due to metabolic alterations and GFR affects rate of excretion.(48) Other routes of excretion are: sweat, saliva, breast milk and digestive juices. ${ }^{(49)}$

\section{Biochemistry of Ill Effects of Fluoride}

There can be acute or chronic changes in an organism due to fluoride exposure. Acute illness may result in nausea, diarrhea, indigestion, gastric discomfort or acidosis. Chronic change due to fluorosis is slow and gradual damage happening from years of fluoride exposure. $(36,26)$

Dental fluorosis- dental fluorosis is early sign of detecting non- skeletal fluorosis. Mechanism of dental fluorosis starts from ameloblasts; cells responsible to secrete and synthesize organic matrix of teeth enamel. During fluorosis, action of fluoride on proteinases (enzyme responsible for enamel's organic matrix synthesis) is inhibitory resulting in precipitation of amelogenin (secreted enamel protein from ameloblasts) on surface of dentine causing plaque formation called 'dental fluorosis'.(50) Accumulated amelogenin may be due to improper protein folding by endoplasmic reticulum which is under stress due to fluorosis.(50) Protein folding failure is one of the major reasons today for ample number of disorders resulted due to fluorosis. Therefore, it the responsibility of many nations to decide whether fluoridation of toothpaste must still be continued or stopped.

There are various indices to assess dental fluorosis, among which Dean's index 1942 and Thylstrup and Fejerskov (1978) indexing are widely accepted.(9,10) Major criteria of these indices are teeth discoloration, mottling of teeth and pitting of enamel. Many epidemiological surveys follow Dean's indexing Community Fluorosis Index (CFI) because its hassle free and has less staging of dental fluorosis. Major demerit in Dean's indexing is lack of sensitivity among different degrees of fluorosis.(51) Therefore, The United States dental researchers from National Institute of Dental Research (NIDR) designed Tooth Surface Index of Fluorosis (TSIF) to avoid flaws raised in various indices. ${ }^{(11)}$ Hence, universally dental fluorosis can be examined precisely by Dean's index or TF index or TSIF index.

Skeletal fluorosis- Initial symptoms of skeletal fluorosis are stiffness and pain in joints and muscle fatigue. Later, it will lead to long bone osteoporosis and subsequently osteosclerosis forming dense bones and frequent fractures.(22) Osteosclerosis is final stage and majorly are seen in low socio-economic group due to illiteracy.(22) Skeletal fluorosis is divided into 4 stages, Stage $I$ is called radiologically dense fluorosis, stage II is pain in joints, stage III is crippling pain fluorosis and stage IV is calcification of ligaments and vertebrae. ${ }^{(52)}$

Skeletal fluorosis is diagnosed by three important physical tests.(52):

i. Chin- to- Chest Test: to touch chest by chin by bending forward.

ii. Coin Test: picking coin on ground without bending knees.

iii. Hands on Occiput Test: to clasp hands behind head on occipital region.

Lab investigation of fluorosis in blood and urine is done by Ion- selective electrode (ISE). Reference range of fluoride in serum and urine are $0.02-0.05 \mathrm{mg} / \mathrm{L}$ and $0.1-1.0 \mathrm{mg} / \mathrm{L}$ respectively.(13)

Non- skeletal fluorosis (Vesicular and vascular): many systems are affected by chronic fluoride exposure such as, thyroid dysfunction, renal tissue damage, neuronal damage, ER stress leading to Type 2 Diabetes Mellitus, liver function deterioration, infertility, gastro- intestinal problems (55-60). In cell, fluoride can inhibit two enzymes: enolase and proton releasing adenosine- triphosphatase (ATPase). Over- 
acidification of cytoplasm can also inhibit the mechanism of glucose transport into cell.

\section{Fluoride in Biological System}

Fluoride is said to cause many ill- effects in an organism. One of the major routes in causing damage to body physiology is reactive oxygen species (ROS) generation by; hence it is also called prooxidant. ROS are oxygen free radicals which disrupts cellular mechanisms leading to improper functioning of tissue causing various pathologies and illness. Renal clearance of fluoride is about $0.5-1 \mathrm{~g} /$ day which varies based on fluoride ingested and glomerular filtration rate (GFR) which based on creatinine clearance. As age progresses fluoride clearance will be high, this leads to slow deterioration of renal function.(37)

Counteraction for fluoride generated ROS is by inclusion of potential antioxidants to nullify fluoride toxicity at molecular level. Fluorosis is a natural phenomenon due to environmental imbalance, the solution for these disturbances also lays in natural forms, hence, antioxidants against fluoride are found majorly in vegetations and plant extracts. To name a few plant sources for counter action are: coffee infusions of different types of beans, Vit E rich sources such as olives, broccoli etc, curcumin a compound in turmeric activates antioxidants cascade in our body, resveratrol prevents ROS generation by breaking free radical chain reaction and prevents lipid peroxidation found in grapes, nuts etc., tamarind fruit pulp rich in vit $\mathrm{C}$ may ameliorate fluoride toxicity by preventing ROS generation, Moringa leaves and its seeds are best in fluoride absorption and excretion from body, also used for water Defluoridation, vit $\mathrm{C}$ rich Emblica officinalis helps deteriorate effect of fluoride on IQ by protecting cholinergic neurotransmitters against fluoride induces ROS damage. It is also evident that fluoride toxicity is alleviated by Aluminium supplements since Al forms AlF complex and is excreted. Therefore, plant sources must be given priority in fluoride endemic areas to lead a quality life by all generations. Other factors triggering fluorosis must also be avoided in order to prevent alleviation of fluorosis example: arsenic when complexed with fluoride enhances non- skeletal fluorosis, lead may cause severe calcification since fluoride as more affinity towards lead but yet to be expanded.

\section{Defluoridation of Drinking Water}

Defluoridation techniques are generally based on principles of ion- exchange, adsorption, precipitation and electrochemical methodology. There are various techniques in water defluoridation, this review briefs only few wellestablished techniques one among them being Nalgonda technique which uses aluminium and lime for flocculation and sedimentation principle of precipitation. Recently, Nalgonda technique is being modified based on the concentration of fluoride in water by either increasing concentration of flocculation material to increase sedimentation rate there by filtering more $\mathrm{F}$. This technique is $82 \%$ effective in filtering fluoride contaminated water.

A study in Mexico revealed that electrocoagulation (EC) can be effectively used to treat fluoride containing groundwater without much water wastage. EC method employs aluminium hydroxide as coagulating medium which forms complex with fluoride by replacing hydroxide ion of the slurry. EC is $80 \%$ effective in removal of fluoride and making water fit to drink. Effectiveness was confirmed by performing X- ray crystallography of slurry output and comparison of water fluoride levels in waters before and after filtration process by ion selective electrode (ISE) method of estimation.

A very popular and conventional method of Defluoridation developed by UNICEF is activated alumina works on adsorption principle. Adsorbent used are natural materials such as red mud composed of aluminium oxides, active seeds of gooseberry rich with vitamin $\mathrm{C}$ and bone char with high carbon content.

Bone char method of water Defluoridation is considered economical because adsorbent can be reused and feasible methodology. Bone char is commercially available which is composed of adding calcium chloride $\left(\mathrm{CaCl}_{2}\right)$ monosodium phosphate $\left(\mathrm{NaH}_{2} \mathrm{PO}_{4}\right)$ and charred animal bones, this method can efficiently remove $92-95 \%$ fluoride from water which is considered the best among all other methodology. Defluoridation efficiencies vary between types of bone chars. There are three different bone chars in decreasing order of their purity such as fresh bone char, regenerated bone char and mixture bone char among which fresh and mixture bone chars are considered efficient in water Defluoridation.

Recent technological advancement in water treatment and purification is membrane bioreactors used for large scale purpose for industrial wastewater treatment. Name of the process suggests membrane bioreactors, which is a combination of conventional biological treatment using latest technological ultrafiltration membranes having advantage over other methods such as volume output of filtered water, lesser sludge production, faster and precise filtration. The major demerit lies in cost and maintenance of membrane.

In India, Fluorosis mitigation is included in $12^{\text {th }}$ year plan by National Programme for Prevention and Control of Fluorosis (NPPCF) Indian health ministry addressing issues on fluorosis state wise and district wise.(53) Drawback of mitigation is follow up and revision of guidelines. Many villages lack properly functioning defluoridation plant eventually making villagers to opt back their conventional bore hole water as their water source which is rich with F.(53) Low socio- economic status also contributes to increase fluorosis incidence. Consuming food rich with Vitamin C, calcium, protein, selenium through milk and vegetables, exposure to sunlight rich with vitamin D helps prevent illeffects of fluorosis.

Other ways to eradicate fluorosis also include estimation of fluoride in drinking water, bottled beverages, industrial effluents, fertilizers and pesticides used for irrigation, soil testing, dental products and air dust. For better correlation of fluorosis in human one must compare soil fluoride levels with serum.(2) Therefore, it must be the responsibility of project incharge to follow up and prevent further illness of fluorosis in population.

\section{Fluoride Analysis}

Broadly, fluoride analysis can be performed by three feasible and accurate methods such as, Ion chromatography, colorimetry and ion selective electrode (ISE). Ion chromatography (IC) is a commercially available nano size zirconia column. Calcium carbonate column for chromatography clarifies effect of fluoride on mineralized 
matrices of animals and human, hence preparation of calcium carbonate dissolved in hydrochloric acid will give precise and accurate results of fluoride in biological system. A major drawback of IC is preparation of column and least accurate compared to other analytical methods. Colorimetric estimation is based on principle of colour development of Fluoride complexed with cation replacing an anion in the reagent. Since colorimetric estimations are most old and restricted to very few sample type and cations hence, replaced recently by Ion selective electrode (ISE) which utilizes lanthanum Fluoride electrode. Major advantage of ISE over any other analytical methods of fluoride analysis are, accuracy, simple to handle and portable for field studies. Minor demerits are, sample volume for analysis is more, electrode is expensive, and method is sensitive for $\mathrm{pH}$ variation of samples. Fluoride ISE is commercially available, to adjust $\mathrm{pH}$ total ionic strength adjusting buffer can be procured or prepared using acetic acid buffer.

\section{CONCLUSIONS}

Eradication of fluorosis is possible by terminating fluoridation of dental products and water, creating awareness among people in fluoride endemic areas and explaining the importance of using defluorinated water for irrigation, growing plants which helps eradicating fluoride from body and avoiding consumables which increases fluoride in body such as tea. Recently, electrocoagulation has been found to be a reliable technique for groundwater defluoridation. Furthermore, research involving fluoride must be taken forward and encouraged by government since fluorosis is not created but naturally happening due to rise in water table by environmental disturbances. Concentrating on regions on fluoride rich belts may help reducing and preventing future complications. Fluoride if introduced in routine blood investigations, especially in fluoride belts, will help in better diagnosis of underlying cause of a pathology or disorder. As a result, future generations will be safe and protected from pathologies and damages caused by fluorosis.

\section{REFERENCES}

[1] Susheela AK, Toteja GS. Prevention \& control of fluorosis \& linked disorders: developments in the $21^{\text {st }}$ century reaching out to patients in the community \& hospital settings for recovery. Indian J Med Res 2018;148(5):53947.

[2] Fawell J, Bailey K, Chilton J, et al. Fluoride in drinkingwater. London: World Health Organization (WHO), 2006. http://Apps.Who.Int/Iris/Bitstream/10665/43514/1/9 241563192_Eng.

[3] Brindha K, Elango L. Fluoride in groundwater: causes, implications and mitigation measures. In: Monroy SD, edr. Fluoride properties, applications and environmental management. Anna University, Chennai, India. 2011;111-36. https://www.novapublishers.com/catalog/product_info. php?products_id=15895
[4] Saravanan S, Kalyani C, Vijayarani M, et al. Prevalence of dental fluorosis among primary school children in rural areas of Chidambaram Taluk, Cuddalore District, Tamil Nadu, India. Indian J Community Med 2008;33(3):14650.

[5] Majumdar KK. Health impact of supplying safe drinking water containing fluoride below permissible level on flourosis patients in a fluoride - endemic rural area of West Bengal. Indian J Public Health 2011;55(4):303-8.

[6] Anand V, Bharatesh KS, Vasudeva G, et al. High prevalence of dental fluorosis among adolescents is a growing concern: a school based cross-sectional study from Southern India. Environmental Health and Preventive Medicine 2017;22:17.

[7] Meththika V, Prosun B. Fluoride in the environment: sources, distribution and defluoridation. Environ Chem Lett 2015;13(2):131-47.

[8] National Toxicology Program Technical Report 393, Toxicology and carcinogenesis studies of sodium fluoride (CAS No. 7681-49-4) In F344/N Rats and B6C3F1 Mice. 1990;355-70. https://Ntp.Niehs.Nih.Gov/Ntp/Htdocs/Lt_Rpts/Tr393. Pdf.

[9] Dean HT. Classification of mottled enamel diagnosis. The Journal of the American Dental Association 1934;21(8):1421-6. DOI: https://doi.org/10.14219/jada.archive.1934.0220.

[10] Thylstrup A, Fejerskov O. Clinical appearance of dental fluorosis in permanent teeth in relation to histologic changes community dentistry and oral epidemiology. 1978;6(6):315-28.

[11] Horowitz HS, Driscoll WS, Meyers RJ, et al. A new method for assessing the prevalence of dental fluorosis - the tooth surface index of fluorosis. author links open overlay panel. Journal of American Dental Association 1984;109(1):37-41.

[12] Rall TW, Sutherland EW. Formation of a cyclic adenine ribonucleotide by tissue particles. J Biol Chem 1958;232(2):1065-76.

[13] Bureau of Indian Standards. Indian Standard Drinking Water - Specification. $2^{\text {nd }}$ Revision. New Delhi: Bureau of Indian Standards, 2012:2.

[14] Chittaranjan D, Uttiya D, Deep C, et al. Fluoride toxicity effects in potato plant (Solanum Tuberosum L) grown in contaminated soils. Octa J Env Res 2015;3(2):136-43.

[15] Shortt HE, Pandit CG, Raghavachari TNS. Endemic fluorosis in Nellore District of South India. Indian Medical Gazettiar 1937;72(7):396-8.

[16] Shortt HE, McRobert GR, Barnard TW, et al. Endemic fluorosis in the Madras presidency. Indian J Med Res 1937;25:553-68.

[17] Choubisa SL. A brief and critical review of endemic hydrofluorosis in Rajasthan, India. Research Review Fluoride 2018;51(1):13-33.

[18] Singh A, Jolly SS, Bansal BC, et al. Endemic fluorosis: epidemiological, clinical and biochemical study of chronic fluorine intoxication in Punjab (India). Medicine (Baltimore) 1963;42:229-46.

[19] Saravanan S, Kalyani C, Vijayarani M, et al. Prevalence of dental fluorosis among primary school children in rural areas of Chidambaram Taluk, Cuddalore District, Tamil 
Nadu, India. Indian J Community Med 2008;33(3):14650.

[20] Mangesh RP, Nandkeshav A, Kalpana KM, et al. Fluorosis in rural area of Marathwada Region of Maharashtra. International Journal of Health Sciences and Research 2015;5(1):1-8.

[21] Fawell J. Fluoride in Drinking - Water. Chapter 3. Background Document for Development of WHO Guidelines for Drinking - Water Quality. 2004:2-3.

[22] Dawes C. What is the critical pH and why does a tooth dissolve in acid? J Can Dent Assoc 2003;69(11):722-4.

[23] Gao HJ, Zhao Q, Zhang XC, et al. Localization of fluoride and Aluminum in subcellular fractions of tea leaves and roots. J Agric Food Chem 2014;62(10):2313-9.

[24] Kubota K, Lee DH, Tsuchiya M, et al. Fluoride induces endoplasmic reticulum stress in ameloblasts responsible for dental enamel formation. J Biol Chem 2005;280(24):23194-202.

[25] Rango T, Vengosh A, Jeuland M, et al. Biomarkers of chronic fluoride exposure in groundwater in a highly exposed population. Science of the Total Environment 2017;596-597:1-11.

[26] Agalakova NI, Gusev GP. Effect of inorganic fluoride on living organisms of different phylogenetic level. Journal of Evolutionary Biochemistry and Physiology 2011;47(5):393-406.

[27] Mondal NK. Diagnosis of fluorosis and recovery through easy to practice interventions. Research report Fluoride 2018;51(3):230-42.

[28] Robinson C, Connell S, Kirkham J, et al. The effect of fluoride on the developing tooth. Caries Res 2004;38(3):268-76.

[29] Badjatia S, Badjatia RG, Thanveer K, et al. Effects of fluoride varnish on streptococcus mutans count in saliva. International Journal of Clinical Pediatric Dentistry 2017;10(1):62-6.

[30] Everett ET. Fluoride's effects on the formation of teeth and bones and the influence of genetics. J Dent Res 2011;90(5):552-60.

[31] Pereira HA, Leite Ade L, Charone S, et al. Proteomic analysis of liver in Rats chronically exposed to fluoride. PLoS One 2013;8(9):e75343.

[32] Waugh DT. Fluoride exposure induces inhibition of sodium/iodide symporter (NIS) contributing to impaired iodine absorption and iodine deficiency: molecular mechanisms of inhibition and implications for public health. Int J Environ Res Public Health 2019;16(6). pii: E1086.

[33] Goschorska M, Baranowska-Bosiacka I, Gutowska I, et al. Potential role of fluoride in the etiopathogenesis of Alzheimer's disease. Int J Mol Sci 2018;19(12). pii: E3965.

[34] Lennon MA, Whelton H, O'Mullane D, et al. Fluoride. Rolling Revision of the WHO Guidelines for DrinkingWater Quality. 2004:2-6.

[35] Whitford GM, Reynoldsa KE, Pashley DH. Acute fluoride toxicity: influence of metabolic alkalosis. Toxicology and Applied Pharmacology 1979;50(1):31-9.
[36] Ullah R, Zafar MS. Oral and dental delivery of fluoride: a review. Research Review Fluoride 2015;48(3):195-204.

[37] Whitford GM, Pashley DH, Reynolds KE. Fluoride tissue distribution: short-term kinetics. Am J Physiol 1979;236(2):141-8.

[38] Ekstrand J, Alvan G, Boreus LO, et al. Pharmacokinetics of fluoride in man after single and multiple oral doses. Eur J Clin Pharmacol 1977;12(4):311-7.

[39] Whitford GM, and Pashley DH, Fluoride absorption: the influence of gastric acidity. Calcif Tissue Int 1984;36(3):302-7.

[40] Jha SK, Mishra VK, Sharma DK, et al. Fluoride in the environment and its metabolism in humans. Rev Environ Contam Toxicol 2011;211:121-42.

[41] Ponikvar M. Exposure of humans to fluorine and its assessment. Fluorine Health 2008: p. 487-549.

[42] Watanabe M, Yoshida Y, Watanabe M, et al. Effect of hydrofluoric acid on glucose metabolism of the mouse studied by whole-body autoradiography. Br J Ind Med 1975;32(4):316-20.

[43] Abou Neel EA, Aljabo A, Strange A, et al. Demineralization- remineralization dynamics in teeth and bone. Int J NanomedicineI 2016;11:4743-63.

[44] Gharzouli K, Amira S, Khennouf S, et al. Effects of sodium fluoride on water and acid secretion, soluble mucus and adherent mucus of the rat stomach. Canadian Journal of Gastroenterology 2000;14(6):493-8.

[45] Yang K, Liang X. Fluoride in drinking water: effect on liver and kidney function. Am Soc of Clin Oncol 2011: p. 769-75.

[46] Bergman C, Gray-Scott D, Chen JJ, et al. What is next for the dietary reference intakes for bone metabolism related nutrients beyond calcium: phosphorus, magnesium, vitamin D, and fluoride? Crit Rev Food Sci Nutr 2009;49(2):136-44.

[47] Buzalaf MAR, Whitford GM. Fluoride metabolism. Monogr Oral Sci 2011;22:20-36.

[48] Manallack DT. The pKa distribution of drugs: application to drug discovery. Perspectives in Medicinal Chemistry 2007;1:25-38.

[49] Bronckers AL, Lyaruu DM, DenBesten PK. The impact of fluoride on ameloblasts and the mechanisms of enamel fluorosis. J Dent Res 2009;88(10):877-93.

[50] Adelário AK, Vilas-Novas LF, Castilho LS, et al. Accuracy of the simplified Thylstrup \& Fejerskov index in rural communities with endemic fluorosis. Int J Environ Res Public Health 2010;7(3):927-37.

[51] Mohammadi AA, Yousefi M, Yaseri M, et al. Skeletal fluorosis in relation to drinking water in rural areas of West Azerbaijan, Iran. Scientific Reports 2017;7:17300.

[52] National Programme for Prevention and Control of Fluorosis (NPPCF) Revised Guidelines. Directorate General of Health Services Ministry of Health \& Family Welfare Government of India. 2014; Annex 1:2.

[53] Khandare AL, Gourineni SR, Validandi V. Dental fluorosis, nutritional status, kidney damage and thyroid function along with bone metabolic indicators in school-going children living in fluoride-affected hilly areas of Doda district, Jammu and Kashmir, India. Environmental Monitoring and Assessment 2017;189(11):579. 